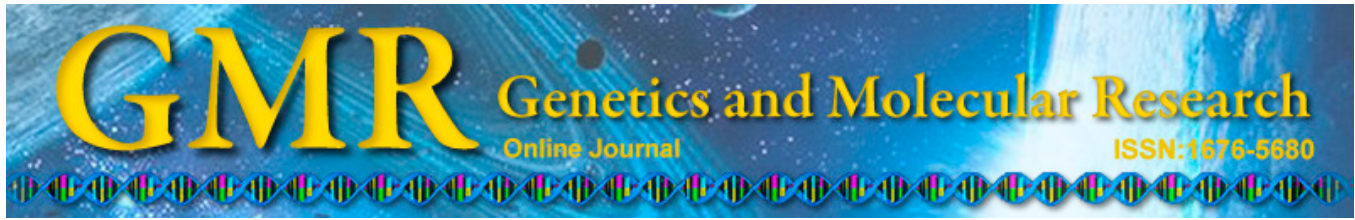

\title{
Analysis of carcass and meat quality traits and nutritional values of hybrid wild boars under different crossing systems
}

\author{
S.-H. Zhang*, L.-Y. Shen*, J. Luo, Z.-H. Wu, Y.-Z. Jiang, G.-Q. Tang, \\ M.-Z. Li, L. Bai, X.-W. Li and L. Zhu \\ College of Animal Science \& Technology, Sichuan Agricultural University, \\ Ya'an, China \\ *These authors contributed equally to this study. \\ Corresponding author: L. Zhu \\ E-mail: zhuli7508@163.com
}

Genet. Mol. Res. 14 (1): 2608-2616 (2015)

Received March 24, 2014

Accepted July 8, 2014

Published March 30, 2015

DOI http://dx.doi.org/10.4238/2015.March.30.20

\begin{abstract}
The aim of this study was to analyze the results of two crossing systems between wild boars and different domesticated pig breeds. Hybrid wild boars were produced by crossing captured wild boars with Meishan pigs and LY sows according to the traditional production system. The resultant commercial hybrids were black and white in coat color, respectively. Significant differences were found in the carcass and meat quality traits and nutritional values between these two hybrid wild boars. Compared with the white hybrid wild boars, at the age of 300 days, the body weight of black hybrid wild boars was $9.41 \mathrm{~kg}$ lower, while percent lean was $2.51 \%$ less and percent fat $2.45 \%$ higher $(\mathrm{P}<0.05)$. The black hybrid wild boars had higher $\mathrm{pH}_{2}$ (6.17 vs 6.09) and intramuscular fat (3.34 vs 2.52\%), lower drip loss (2.21 vs $2.68 \%)$ and shear force (44.00 vs 52.23) $(\mathrm{P}<0.05)$, and more unsaturated fatty acids and essential amino acids $(\mathrm{P}<0.05)$. In conclusion, cross breeding was shown to be an effective method to improve the overall production performance of wild boars, but crossing
\end{abstract}


with different dam line breeds caused different responses. Compared with the white hybrid wild boars, the black hybrid wild boars had worse growth rate and carcass traits, but better meat quality traits and nutritional values.

Key words: Wild boars; Hybrid system; Carcass; Meat quality; Nutritional value

\section{INTRODUCTION}

With the development of the economy, the demand for high quality pork has continued to increase in China. Now, the research and development of high quality pork is a hot topic in China. China owns the most abundant indigenous pig breeds in the world, and these pig breeds are famous for their excellent meat quality and reproduction performance (Warriss et al., 1996; Lu et al., 2008; Cesar et al., 2010; Lee et al, 2012). But the exploitation and development of indigenous pig breeds is just beginning in China. On the other hand, Chinese continue the tradition of consuming wild boars. Wild boars are treated as an animal of economic importance in China, because they have good meat quality and disease resistance ability. However, they have poor reproduction performance, feed conversion rate, and low intramuscular fat (IMF) content (Marsico et al., 2007). Crossing is a highly effective method in pig production to improve the carcass and meat quality of commercial pigs (Lan et al., 1993; Young, 1995, 1998; Edwards et al., 2003; Verónica et al., 2009; Cesar et al., 2010; Jiang et al., 2012). How to introduce the high reproduction performance and IMF content of Chinese indigenous pig breeds and the high feed conversion rate and carcass performance of Western pig breeds into the crossing system of wild boars, is becoming more and more important (Marsico, 2007). According to published studies, the hybrids between wild boars and Chinese indigenous pigs have the benefits of higher percent lean, better taste, and higher nutritional value. The hybrids between wild boars and Western pigs showed hybrid vigor in growth performance (Marsico, 2007).

The mountainous areas of Sichuan Province are rich in wild boars. The local farmers continue the practice of crossing captured wild boars with Meishan pigs and Western breeding sows to improve the production performance. To evaluate the effect of different crossing systems, captured wild boars were bred with Meishan pigs and LY sows in this study. The resultant commercial hybrids were black and white in coat color, respectively. The carcass and meat quality traits and nutritional values between these two hybrid wild boars were analyzed to evaluate the crossing system of wild boars. The results can be used to protect and develop the wild boar resource, and to breed some special commercial lines with those originating from wild boars in the future.

\section{MATERIAL AND METHODS}

The experimental protocol was approved by the Animal Care and Ethics Committee of Sichuan Agricultural University, China.

\section{Animals and management}

Commercial hybrid wild boars originated from crossing captured wild boars with 
Meishan pigs and LY (Landrace x Yorkshire) sows were utilized in this study. The resultant commercial hybrids from Meishan pigs were black in coat color (black hybrid wild boars), and those from LY sows were white in coat color (white hybrid wild boars). Twenty black hybrid wild boars and 20 white hybrid wild boars were castrated on the 5 th day after birth and raised under the same uniform conditions in the Bazhong wild boar breeding farm. All of these hybrid wild boars were slaughtered at the same age of 300 days. The carcass and meat quality traits and nutritional values of these hybrid wild boars were measured in the slaughter testing.

\section{Carcass trait measurements}

Animals were transferred to an abattoir and fasted overnight, for $24 \mathrm{~h}$ prior to harvest, and were only allowed to have free access to water. On the day of harvest, all pigs were harvested according to humane, standard commercial procedures (Xiao et al., 1999). The carcass traits were measured following the procedures described below. Briefly, dressing percentage was determined from the slaughter weight (animals weighed after fasting overnight with free access to water) and the hot carcass weight was determined using the following formula: dressing percentage $(\%)=$ carcass weight $(\mathrm{kg}) /$ slaughter weight $(\mathrm{kg}) \cdot 100 \%$. The carcass was split longitudinally and the backfat thickness was the average value measured with a sliding caliper at three points: the first rib, last rib, and last lumbar vertebra along the midline. The loin eye area was measured on the cross-sectional area of the longissimus thoracis from the 6th rib and was calculated by: loin area $\left(\mathrm{cm}^{2}\right)=$ length $(\mathrm{cm}) \cdot$ height $(\mathrm{cm}) \cdot 0.7$. The bone, muscle, subcutaneous fat and skin of right carcass were physically dissected and then weighed, and the relative percentages $(\%)$ were calculated.

\section{Meat quality trait measurements}

Meat color (CIE L) was objectively measured at $45 \min \left(\mathrm{L}_{1}\right)$ and $24 \mathrm{~h}\left(\mathrm{~L}_{2}\right)$ postmortem, at the longissimus thoracis muscle cutting surface between the 9th and 10th rib using the Model CR-300 Minolta Chroma Meter (Minolta Corp, Osaka, Japan) with an illuminant D65, and standardized against a white plate. Muscle $\mathrm{pH}$ values were measured at $45 \mathrm{~min}$ $\left(\mathrm{pH}_{1}\right)$ and $24 \mathrm{~h}\left(\mathrm{pH}_{2}\right)$ postmortem, at approximately one centimeter below the cutting surface of the longissimus thoracis muscle from the 10th to 11th rib using a $\mathrm{pH}$ Star meter (SFK Inc., Denmark). The longissimus thoracis from the 9th to 10 th rib, stored at $-20^{\circ} \mathrm{C}$ for $24 \mathrm{~h}$, was used for estimating marbling scores according to the method of the National Pork Producers Council (NPPC, 2000). Dripping loss was measured by the plastic bag method (Young et al., 2009). Warner-Bratzler shear force (WBSF) was measured according to the protocol described by Crawford et al. (2010). Three 1.27-cm diameter cores of longissimus thoracis sample were measured using a TA.XT.plus Texture Analyser (Stable Micro System Ltd, UK), and WBSF was recorded as the average peak shear force measured.

\section{Chemical composition}

Meat moisture content was measured by drying with a $105^{\circ} \mathrm{C}$ oven. Crude protein was measured by the Kjeldahl method. Crude fat was measured by the Soxhlet extraction method. Ash content was measured by calcination in a $550^{\circ} \mathrm{C}$ ashing furnace. 


\section{Free amino acid measurements}

Amino acid composition was determined using the method described by $\mathrm{Lu}$ et al. (2008). The wet muscle samples were cut into slices and dried in a vacuum-freeze dryer, allowed to equilibrate with atmospheric moisture for $24 \mathrm{~h}$, and then finely ground to pass a 60 -mesh sieve. The amino acid composition of the muscle powder was analyzed using ionexchange chromatography with an automatic amino acid analyzer (L-8800 Hitachi Automatic Amino Acid Analyzer, Tokyo, Japan) after hydrolysis with $6 \mathrm{~N} \mathrm{HCl}$ at $110^{\circ} \mathrm{C}$ for $24 \mathrm{~h}$. Methionine, cystine and tryptophan were partly destroyed under acid hydrolysis. Tryptophan was determined after alkaline hydrolysis with $4 \mathrm{~N} \mathrm{NaOH}$ for $22 \mathrm{~h}$ at $110^{\circ} \mathrm{C}$. Methionine and cystine were analyzed after cold formic acid oxidation for $16 \mathrm{~h}$ before acid hydrolysis. Duplicate analyses were performed on all samples.

\section{Free fatty acid measurements}

Free fatty acid (FA) composition was analyzed by gas chromatography (Agilent 6820, Agilent Technologies, USA) using a capillary column (HP-Innowax, Agilent, $30 \mathrm{~m}$ long, 0.32 $\mathrm{mm}$ internal diameter and $0.25 \mathrm{~mm}$ film thickness) according to the method described by Yang et al. (2005). The temperature program was started at $200^{\circ} \mathrm{C}$ for $2 \mathrm{~min}$, followed by ramping to $202^{\circ} \mathrm{C}$ at a rate of $0.48^{\circ} \mathrm{C} / \mathrm{min}$, and then followed by another ramping to $207^{\circ} \mathrm{C}$ at a rate of $0.7^{\circ} \mathrm{C} / \mathrm{min}$ and holding for $14 \mathrm{~min}$. The temperature of the injection port was $250^{\circ} \mathrm{C}$ and that of the flame ionization detector was $275^{\circ} \mathrm{C}$. The velocity of the carrier gas (N2) was set at 2.8 $\mathrm{mL} / \mathrm{min}$ and the head pressure of the carrier gas was $11.9 \mathrm{psi}$. FAs in three fractionations were quantified using C17:0 as an internal standard. All FAs in the samples were identified by the retention times according to the standard FAs (Sigma Chemical Co., St. Louis, MO, USA).

\section{Statistical analysis}

All data were analyzed with SAS (SAS 9.2, SAS Inst. Inc., Cary, NC). The ANOVA procedure was used to analyze the difference between the two hybrid wild boars. The model included hybrid breed as the main effect. The Duncan test was applied to compare the mean values of the hybrid breeds. Differences were considered to be statistically significant when $\mathrm{P}<0.05$.

\section{RESULTS}

\section{Growth and carcass traits of the two hybrid wild boars}

Table 1 shows that compared with the reported performances of pure wild boars (Marsico et al., 2007), both hybrid wild boars had better growth and carcass performance. The growth rate of black hybrid wild boars was slower compared to white hybrid boars, and the body weight at the age of 300 days was $9.41 \mathrm{~kg}$ lighter $(\mathrm{P}<0.05)$. Compared with white hybrid boars, the black hybrid boars had worse carcass traits: the lean percent was $2.51 \%$ less, backfat thickness $0.30 \mathrm{~cm}$ thicker, and percent fat $2.45 \%$ higher $(\mathrm{P}<0.05)$. As to the dressing percentage, loin eye area, ham rate and bone percentage, there were no significant differences $(\mathrm{P}>0.05)$. In summary, the white hybrid wild boars had better growth rate and carcass performances. 
Table 1. Carcass traits in the two hybrid wild boars.

\begin{tabular}{lcc}
\hline Traits & Black hybrid wild boars & White hybrid wild boars \\
\hline Body weight $(\mathrm{kg})^{*}$ & $83.42 \pm 3.41^{\mathrm{a}}$ & $92.83 \pm 2.28^{\mathrm{b}}$ \\
Dressing percentage (\%) & $72.58 \pm 2.89$ & $72.97 \pm 3.23$ \\
Average backfat thickness (cm)** & $2.29 \pm 0.11^{\mathrm{a}}$ & $1.99 \pm 0.03^{\mathrm{b}}$ \\
Loin eye area $\left(\mathrm{cm}^{2}\right)$ & $26.43 \pm 2.48$ & $28.08 \pm 1.61$ \\
Ham rate (\%) & $28.23 \pm 1.86$ & $28.69 \pm 1.14$ \\
Carcass lean percentage (\%) & $64.67 \pm 3.66^{\mathrm{a}}$ & $67.18 \pm 2.79^{\mathrm{b}}$ \\
Carcass fat and skin (\%) & $21.84 \pm 0.74^{\mathrm{a}}$ & $19.39 \pm 0.89^{\mathrm{b}}$ \\
Carcass bone (\%) & $14.10 \pm 0.78$ & $13.43 \pm 0.64$ \\
\hline
\end{tabular}

*Means the body weight at he age of 300 days; **means the average backfat thickness of three points measured on the fist rib, last rib, and last lumbar vertebra along the midline; means within a row with different superscripts indicate significant differences $(\mathrm{P}<0.05)$.

\section{Meat quality traits of the two hybrid wild boars}

The meat quality traits of the two hybrid wild boars are shown in Table 2. Compared with white hybrid wild boars, the black hybrid wild boars had better meat quality traits, $\mathrm{pH}_{1}$, $\mathrm{pH}_{2}$, and marbling score were significantly higher $(\mathrm{P}<0.05)$, and the drip loss and shear force were significantly lower $(\mathrm{P}<0.05)$. There was no significant difference for meat color $\left(\mathrm{L}_{1}\right.$ and $\left.\mathrm{L}_{2}\right)(\mathrm{P}>0.05)$. In summary, the black hybrid wild boars had better meat quality traits.

Table 2. Meat quality traits in the two hybrid wild boars.

\begin{tabular}{lcr}
\hline Traits & Black hybrid wild boars & White hybrid wild boars \\
\hline $\mathrm{L}_{1}{ }^{*}$ & $33.65 \pm 1.0$ & $35.38 \pm 0.03$ \\
$\mathrm{~L}_{2}{ }^{* *}$ & $37.17 \pm 0.52$ & $38.66 \pm 3.17$ \\
$\mathrm{pH}_{1}{ }^{* *}$ & $6.84 \pm 0.36^{\mathrm{a}}$ & $6.53 \pm 0.20^{\mathrm{b}}$ \\
$\mathrm{pH}_{2}{ }^{\mathrm{b}}$ & $6.17 \pm 0.03^{\mathrm{a}}$ & $6.09 \pm 0.18^{\mathrm{b}}$ \\
Marbling score & $3.25 \pm 0.69^{\mathrm{a}}$ & $2.74 \pm 0.32^{\mathrm{b}}$ \\
Drip loss $(\%)$ & $2.21 \pm 0.71^{\mathrm{a}}$ & $2.68 \pm 0.56^{\mathrm{b}}$ \\
Share force $(\mathrm{N})$ & $44.00 \pm 4.75^{\mathrm{a}}$ & $52.23 \pm 5.45^{\mathrm{b}}$ \\
\hline
\end{tabular}

$* \mathrm{~L}_{1}$ and $\mathrm{pH}_{1}$ were measured at 45 min post-mortem; $* * \mathrm{~L}_{2}$ and $\mathrm{pH}_{2}$ were measured at $24 \mathrm{~h}$ post-mortem; means within a row with different superscripts indicate significant differences $(\mathrm{P}<0.05)$.

\section{Chemical composition of the two hybrid wild boars}

Table 3 shows the general chemical composition of the longissimus dorsi in the two hybrid wild boars. The black hybrid wild boars had less moisture content and more fat (IMF) than did white hybrid wild boars $(\mathrm{P}<0.05)$. There were no significant differences for protein and ash content $(\mathrm{P}>0.05)$. Normally, the reported fat content of natural wild boars is $1.55 \%$ (Marsico et al., 2007), the improvement of fat (IMF) in both hybrid wild boars can result in better eating quality (Cameron and Enser, 1991).

\begin{tabular}{lcr}
\multicolumn{2}{c}{ Table 3. Chemical composition in the two hybrid wild boars. } \\
\hline Traits & Black hybrid wild boars & White hybrid wild boars \\
\hline Moisture (\%) & $69.38 \pm 3.25^{\mathrm{a}}$ & $71.21 \pm 2.53^{\mathrm{b}}$ \\
Fat (\%) & $3.34 \pm 0.12^{\mathrm{a}}$ & $2.52 \pm 0.09^{\mathrm{b}}$ \\
Protein (\%) & $24.53 \pm 1.16$ & $23.24 \pm 0.83$ \\
Ash (\%) & $1.17 \pm 0.08$ & $1.18 \pm 0.14$ \\
\hline
\end{tabular}

Means within a row with different superscripts indicate significant differences $(\mathrm{P}<0.05)$. 


\section{Free fatty acid composition of the two hybrid wild boars}

Table 4 shows the FAs of the longissimus dorsi in the two hybrid wild boars. In this study, C18:1, C16:0, C18:0, and C18:2 were the main FAs; meanwhile, monounsaturated fatty acid and saturated fatty acid were by far the most abundant components $(>85 \%)$ in the longissimus dorsi. These results were in good agreement with the results of other reports (Martin et al., 2008; Jiang et al., 2011). As to the different hybrid groups, the longissimus dorsi of black hybrid wild boars had more unsaturated fatty acid (UFC) than that of white hybrid wild boars, especially $\mathrm{C} 18: 2$ and $\mathrm{C} 20: 2(\mathrm{P}<0.05)$.

\begin{tabular}{|c|c|c|}
\hline Traits & Black hybrid wild boars & White hybrid wild boars \\
\hline C14:0 & $0.72 \pm 0.33$ & $0.88 \pm 0.28$ \\
\hline $\mathrm{C} 15: 0$ & $0.26 \pm 0.06$ & $0.17 \pm 0.04$ \\
\hline $\mathrm{C} 16: 0$ & $19.02 \pm 2.68$ & $19.75 \pm 2.48$ \\
\hline C16:1 & $1.71 \pm 0.92$ & $1.69 \pm 0.67$ \\
\hline $\mathrm{C} 17: 0$ & $0.22 \pm 0.26^{\mathrm{a}}$ & $0.34 \pm 0.24^{\mathrm{b}}$ \\
\hline $\mathrm{C} 17: 1$ & $1.06 \pm 0.02$ & $1.06 \pm 0.01$ \\
\hline C18:0 & $16.02 \pm 2.76^{\mathrm{a}}$ & $17.75 \pm 0.69^{b}$ \\
\hline C18:1 & $43.10 \pm 3.72$ & $42.96 \pm 5.41$ \\
\hline $\mathrm{C} 18: 2$ & $10.13 \pm 2.04^{\mathrm{a}}$ & $7.19 \pm 1.26^{\mathrm{b}}$ \\
\hline C19:0 & $1.09 \pm 0.05$ & $1.09 \pm 0.06$ \\
\hline $\mathrm{C} 20: 0$ & $1.17 \pm 0.13$ & $1.11 \pm 0.06$ \\
\hline $\mathrm{C} 20: 1$ & $1.57 \pm 0.35$ & $1.75 \pm 0.27$ \\
\hline $\mathrm{C} 20: 2$ & $1.54 \pm 0.12^{\mathrm{a}}$ & $1.23 \pm 0.13^{\mathrm{b}}$ \\
\hline $\mathrm{C} 20: 3$ & $1.10 \pm 0.14$ & $1.02 \pm 0.02$ \\
\hline $\mathrm{C} 20: 4$ & $1.29 \pm 0.91$ & $2.01 \pm 0.41$ \\
\hline SFA & $38.50 \pm 3.51^{\mathrm{a}}$ & $41.09 \pm 4.17^{b}$ \\
\hline UFA & $61.50 \pm 3.74^{\mathrm{a}}$ & $58.91 \pm 3.64^{b}$ \\
\hline MUFA & 47.44 & 47.46 \\
\hline PUFA & 14.06 & 11.45 \\
\hline UFA/SFA & 1.60 & 1.43 \\
\hline PUFA/SFA & 0.37 & 0.28 \\
\hline
\end{tabular}

Means within a row with different superscripts indicate significant differences $(\mathrm{P}<0.05)$.

\section{Free amino acid composition of the two hybrid wild boars}

Table 5 shows the free amino acids of the longissimus dorsi in the two hybrid wild boars. All of the eight essential amino acids (EAAs) were found in the two hybrid wild boars, with leucine, methionine, and lysine showing the highest content. These results were in good agreement with the results of other reports (Okrouhlá et al., 2006; Jiang et al., 2011). Although no significant differences were found for the total EAAs between the two groups $(\mathrm{P}>0.05)$, the content of histidine, an EEA for children (or semi- EAA), was significantly higher in black hybrid boars $(\mathrm{P}<0.05)$.

\section{DISCUSSION}

Chinese have the tradition of eating wild animals. As an animal economic importance, wild boars have been treated as a top grade palatable and delicious meat resource. To Chinese, the meat of wild boars has a special flavor, but it also has some disadvantages, namely less IMF and poor growth performance (Marsico et al., 2007). With the development of the 
economy, the market requirement of wild boars has continued to increase in China in the past decades. Because the quantity of natural wild boars is limited, many efforts have been made to meet the increasing market demand. Crossing the natural wild boars with domestic pig breeds to produce hybrid wild boars is an effective method. Many studies have proven that crossing with domestic pig breeds can improve the overall production performance of wild boars (Martin et al., 2007). But it is hard to say what kind of crossing system is the best hybrid system. Choosing different dam line breeds can result in different commercial hybrids. On the other hand, in the Chinese market, people pay special attention to the coat color of commercial pigs. How to produce high quality hybrid wild boars with different coat color is very important for market exploitation. In this study, we chose two of the most popular domestic pig breeds in China to form two different crossing systems. One is Meishan pig (a Chinese indigenous pig breed, with black coat color), and the other is the two-way hybrid sow from Landrace $\mathrm{x}$ Yorkshire (LY) (a modern Western pig breed, with white coat color), where both of them are the most widely used pig breeds in China, especial in mountainous areas. As expected, the coat color of hybrid boars was consistent with the dam line. We obtained black hybrid wild boars from Meishan pigs and white hybrid wild boars from LY sows.

Table 5. Free amino acid composition of the two hybrid wild boars (mg/100g).

\begin{tabular}{lcr}
\hline Traits & Black hybrid wild boars & White hybrid wild boars \\
\hline Lysine* & $7.80 \pm 0.35$ & $8.69 \pm 2.37$ \\
Leucine* $^{*}$ & $9.45 \pm 1.33$ & $9.64 \pm 2.08$ \\
Isoleucine* & $4.75 \pm 0.74$ & $4.53 \pm 0.63$ \\
Valine* & $5.59 \pm 0.02$ & $5.65 \pm 1.65$ \\
Phenylalanine* & $6.32 \pm 0.28$ & $6.35 \pm 0.54$ \\
Tryptophan* & $1.67 \pm 0.10$ & $1.54 \pm 0.33$ \\
Threonine* & $6.29 \pm 1.11$ & $5.94 \pm 1.16$ \\
Methionine* & $8.03 \pm 0.01$ & $8.33 \pm 0.34$ \\
Histidine & $6.92 \pm 1.73^{\mathrm{a}}$ & $5.18 \pm 1.99^{\mathrm{b}}$ \\
Tyrosine & $7.18 \pm 3.35^{\mathrm{a}}$ & $5.88 \pm 0.47^{\mathrm{b}}$ \\
Aspartic acid & $1.76 \pm 0.32$ & $1.67 \pm 0.93$ \\
Arginine & $6.19 \pm 0.34$ & $5.87 \pm 0.91$ \\
Glycine & $10.13 \pm 0.35^{\mathrm{a}}$ & $8.84 \pm 1.59^{\mathrm{b}}$ \\
Serine & $8.32 \pm 1.22$ & $8.28 \pm 2.34$ \\
Proline & $7.52 \pm 1.85$ & $7.12 \pm 1.08$ \\
Asparagine & $3.08 \pm 0.81$ & $2.99 \pm 0.31$ \\
Glutamine & $17.17 \pm 3.92$ & $16.36 \pm 1.29$ \\
Taurine & $16.40 \pm 7.32^{\mathrm{a}}$ & $12.63 \pm 3.02^{\mathrm{b}}$ \\
Citrulline & $1.58 \pm 0.53$ & $1.29 \pm 0.19$ \\
Ethanolamine & $22.38 \pm 2.39^{\mathrm{a}}$ & $25.71 \pm 4.04^{\mathrm{b}}$ \\
Carnosine & $44.28 \pm 5.99^{\mathrm{a}}$ & $47.44 \pm 5.91^{\mathrm{b}}$ \\
Anserinenitrate & $7.08 \pm 1.22$ & $7.08 \pm 1.08$ \\
EAA & 49.9 & 50.67 \\
EA & &
\end{tabular}

*Means essential amino acid, the others are non-essential amino acid; EAA = essential amino acid; means within a row with different superscripts indicate significant differences $(\mathrm{P}<0.05)$.

In this study, both crossing systems resulted in overall improvement of growth and carcass and meat quality traits of hybrid boars. These results were in good agreement with the results of other reports (Marsico et al., 2007). At the same time, a different dam line breed resulted in a different response. With the modern Western pig breed origin, the white hybrid boars had higher body weight at 300 days, higher carcass lean percentage and lower backfat thickness, and overall, exhibited better growth rate and carcass performances. At the same time, the black hybrid wild boars, with Chinese indigenous pig breed origin, had higher $\mathrm{pH}$ 
(both $\mathrm{pH}_{1}$ and $\mathrm{pH}_{2}$ ) and IMF, lower drip loss and shear force, and more UFC and aromatic amino acids; overall, they had better meat quality and nutritional values (Cameron et al., 1991; Boler et al., 2010; Yang et al., 2010).

From a genetic point of view, even to be exploited as an important commercial animal, the wild boar is essentially a wild animal. Long time living in the natural world keeps evolution only under natural selection pressure. The absence of artificial selection pressure, and the wide genetic distance with domestic pig breeds has resulted in excellent heterosis in the F1 hybrid boars. As noted above, in almost all of the previous reports, regardless of the kinds of hybrid combinations, positive heterosis were found in F1 hybrids boars (Marsico et al., 2007). All these facts proved that crossing is the most effective method to improve the economic performance of wild boars. But till now, nobody performed further research to examine the conditions of F2 hybrid or genetic response to further generation of hybrids. How to maximize heterosis and to keep the positive heterosis passing on to the next generation in the hybrid production system, is a big issue worthy of further study.

\section{CONCLUSION}

In summary, both crossing systems between wild boars and domestic pig breeds, either Chinese indigenous pig or modern Western pig, improved the carcass and meat quality traits and nutritional values greatly. These results indicated that cross breeding could be an effective method to improve the overall production performance of wild boars, but crossing with different dam line breeds caused different responses. Generally speaking, crossing with modern Western breeds can improve the growth rate and carcass traits, and crossing with Chinese indigenous pig breeds can improve the meat quality and nutritional values.

\section{ACKNOWLEDGMENTS}

Research supported by the Earmarked Fund for China Agriculture Research System (\#CARS-36-05B), Sichuan Sci \& Tech Support Program (\#2013NZ0041, \#2012NZ001), Initiation Foundation Project of Chinese Education Ministry, and National Sci \& Tech Support Program (\#2013BAD20B07). All the work was performed at Farm Animal Genetic Resources Exploration and Innovation Key Laboratory of Sichuan Province, Sichuan Agricultural University.

\section{REFERENCES}

Boler DD, Dilger AC, Bidner BS, Carr SN, et al. (2010). Ultimate pH explains variation in pork quality. J. Mus. Foods 21: $119-130$

Cameron N and Enser M (1991). Fatty acid composition of lipid in Longissimus dorsi muscle of Duroc and British Landrace pigs and its relationship with eating quality. Meat Sci. 29: 295-307.

Crawford SM, Moeller SJ, Zerby HN, Irvin KM, et al. (2010). Effects of cooked temperature on pork tenderness and relationships among muscle physiology and pork quality traits in loins from Landrace and Berkshire swine. Meat Sci. 84: 607-612.

Cesar ASM, Silveira ACP, Freitas PFA, Guimarāes EC, et al. (2010). Influence of Chinese breeds on pork quality of commercial pig lines. Genet. Mol. Res. 9: 727-733.

Edwards DB, Bates RO and Osburn WN (2003). Evaluation of Duroc vs Pietrain sired pigs for carcass and meat quality measures. J. Anim. Sci. 81: 1895-1899.

Jiang YZ, Zhu L, Li XW and Si T (2011). Evaluation of the Chinese indigenous pig breed Dahe and crossbred Dawu 
for growth and carcass characteristics, organ weight, meat quality and intramuscular fatty acid and amino acid composition. Animal 5: 1485-1492.

Jiang Y, Zhu L, Tang G, Li M, et al. (2012). Carcass and meat quality traits of four commercial pig crossbreeds in China. Genet. Mol. Res. 11: 4447-4455.

Lan YH, McKeith FK, Novakofski J and Carr TR (1993). Carcass and muscle characteristics of Yorkshire, Meishan, Yorkshire x Meishan, Meishan x Yorkshire, Fengjing x Yorkshire, and Minzhu x Yorkshire Pigs. J. Anim. Sci. 71: 3344-3349.

Lee SH, Choe JH, Choi YM, Jung KC, et al. (2012). The influence of pork quality traits and muscle fiber characteristics on the eating quality of pork from various breeds. Meat Sci. 90: 284-291.

Lu P, Li DF, Yin JD, Zhang LY and Wang ZY (2008). Flavour differences of cooked longissimus muscle from Chinese indigenous pig breeds and hybrid pig breed (Duroc 3 Landrace 3 Large White). Food Chemistry 107: 1529-1537.

Marsico G, Rasulo A, Dimatteo S, Tarricone S, et al. (2007). Pig, F1 (wild boar x pig) and wild boar meat quality. Italian J. Anim. Sci. 6 (Suppl 1): 701-703.

Martin D, Muriel E, Antequera T, Perez-Palacios T, et al. (2008). Fatty acid composition and oxidative susceptibility of fresh loin and liver from pigs fed conjugated linoleic acid in combination with monounsaturated fatty acids. Food Chem. 108: 86-96.

National Pork Produces Council (NPPC) (2000). Pork Composition and Quality Assessment Procedures. 1st edn. NPPC, Des Moines, IA, USA.

Okrouhlá M, Stupka R, Citek J, Sprysl M, et al. (2006). Amino acid composition of pig meat in relation to live weight and sex. Czech J. Anim. Sci. 51: 529-534.

Verónica A, Mariá del MC, Sonia E, Pedro R and José AB (2009). Effect of crossbreeding and gender on meat quality and fatty acid composition in pork. Meat Sci. 81: 209-217.

Warriss PD, Kestin SC, Brown SN and Nute GR (1996). The quality of pork from traditional pig breeds. Meat Focus Int. 5: $179-183$.

Xiao RJ, Xu ZR and Chen HL (1999). Effects of ractopamine at different dietary protein levels on growth performance and carcass characteristics in finishing pigs. Anim. Feed Sci. Technol. 79: 119-127.

Yang HG, Ma CW, Qiao FD, Song Y and Du M (2005). Lipolysis in intramuscular lipids at processing of traditional Xuanwei ham. Meat Sci. 71: 670-675.

Yang Y, Zhao CJ, Xiao S, Zhan H, et al. (2010). Lipids deposition, composition and oxidative stability of subcutaneous adipose tissue and Longissimus dorsi muscle in Guizhou mini-pig at different developmental stages. Meat Sci. 84: 684-690.

Young JF, Bertram HC and Oksbjerg N (2009). Rest before slaughter ameliorates pre-slaughter stress-induced increased drip loss but not stress-induced increase in the toughness of pork. Meat Sci. 83: 634-641.

Young LD (1995). Survival, body weights, feed efficiency, and carcass traits of 3/4 white composite and 1/4 Duroc, 1/4 Meishan, 1/4 Fengjing, or 1/4 Minzhu pigs. J. Anim. Sci. 73: 3534-3542.

Young LD (1998). Survival, body weights, feed efficiency, and carcass traits of 7/8 White Composite and 1/8 Duroc, 1/8 Meishan, 1/8 Fengjing, or 1/8 Minzhu pigs. J. Anim. Sci. 76: 1550-1558. 